\title{
Kinetic acidity of methane ${ }^{1}$
}

\author{
Andrew Streitwieser* and David R. Taylor \\ Department of Chemistry, University of California, Berkeley 95720-1460 \\ E-mail: astreit@socrates.berkeley.edu
}

Dedicated to Professor Gerasimos J. Karabatsos on his $70^{\text {th }}$ birthday

(received 12 Feb 03; accepted 14 Jul 03; published on the web 15 Jul 03)

\begin{abstract}
Hydrogen isotope exchange kinetics catalyzed by cesium cyclohexylamide at $50{ }^{\circ} \mathrm{C}$ were studied for methane- $d$ in cyclohexylamine and for methane in cyclohexylamine-N,N- $d_{2}$. The complex kinetics were modeled using Excel spreadsheets and showed satisfactory agreement with the experimental points. The kinetic acidity of methane is 7000 times that of cyclohexane and 4.0E4 times that of benzene.
\end{abstract}

Keywords: Methane, carbanions, methylcesium, hydrogen isotope exchange, spreadsheet, kinetics

\section{Introduction}

Three decades ago we published some preliminary results on the hydrogen isotope exchange of methane with cesium cyclohexylamide (CsCHA) in cyclohexylamine (CHA) as a measure of the effective acidity of methane in solution. ${ }^{2}$ We have published related results with cyclohexane and other cycloalkanes. ${ }^{3-5}$ The latter exchange reactions are slow but could be followed straightforwardly using tritium as a tracer. Methane, however, exchanges much more rapidly and being a gas introduced additional complexities that could not be handled satisfactorily at that time. The data were reanalyzed recently using an Excel spreadsheet to model the kinetics. Good reproducibility was obtained with a more accurate measure of the kinetic acidity of methane that can now be compared to other alkanes. The methane kinetics will be detailed in the present paper. The comparison with other alkanes will be published separately. The complete results are of value to the current interest in "hydrocarbon activation" and for comparison with theoretical models. ${ }^{6}$ Despite of the fundamental nature of methane in chemistry no comparable data are available. 


\section{Results and Discussion}

Protodedeuteration. Run DRT-11 involved the reaction only of methane- $d$ with CsCHA in CHA in order to determine the s order rate constant for comparison with other compounds. The kinetics is not completely straightforward because the amount of methane $(8.31 \mathrm{mmol})$ is significant compared to the CHA (715 mmol) used; thus, at equilibrium a substantial amount of deuterium remains in the methane and the reaction rate gradually slows as the deuterium content of the solvent grows. This type of problem was encountered in our earliest work on the protodedeuteration of toluene- $\alpha-d$ with lithium cyclohexylamide (LiCHA) and equations were derived to handle this complexity ${ }^{7}$. In the present study the data were analyzed by simulation on an Excel spreadsheet based on the reaction mechanism shown in Scheme 1, in which the methylcesium is treated as a steady state intermediate.

Computer programs for the numerical integration of complex kinetics have long been available, but using spreadsheets for this purpose has the decided advantage of rapid feedback in real time with interactive adjustment of parameters.

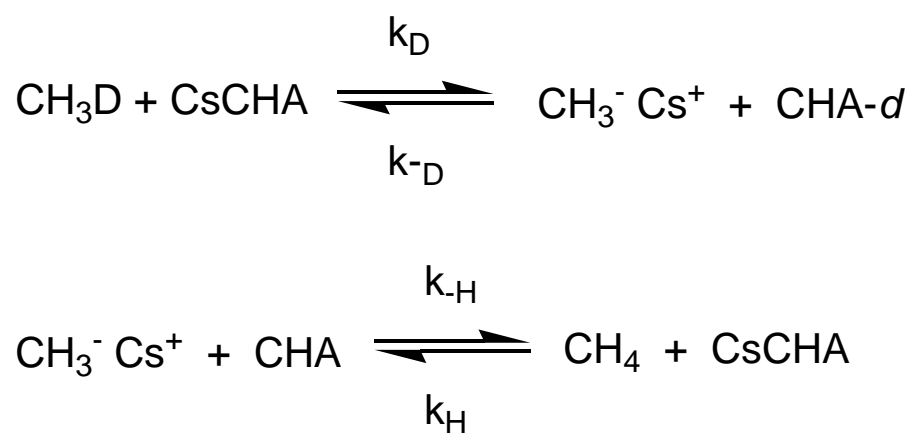

\section{Scheme 1}

The general use of spreadsheets for this purpose is well known. ${ }^{9}$ Each column represents a reactant, product or intermediate. Each row is a new time increment with concentrations calculated from those on the preceding row. The time increments between rows $(\Delta t)$ are kept as small as possible in order that the finite differences approach a differential. That is, spreadsheets of over 1000 rows were used. The calculated concentrations in each cell could be plotted to give the simulated kinetics; with this many points the simulation looks like continuous curves. The experimental points can be compared directly with such simulations.

The approach is shown for the change in $\left[\mathrm{CH}_{3} \mathrm{D}\right] \equiv \mathrm{D}_{1}$. The change in $\mathrm{D}_{1}$ is given by eq. 1 . The use of the steady state approximation for MeCs the gives eq. 2.

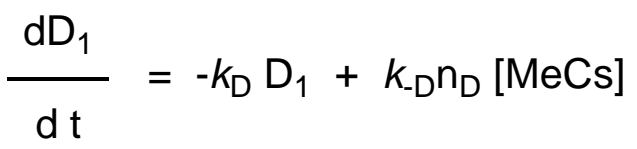




$$
\frac{d D_{1}}{d t}=-k_{D} D_{1}+k_{D} \frac{n_{D}}{n_{D}+\lambda n_{H}}\left(D_{1}+4 \lambda D_{0}\right)
$$

Eq. 1 is primarily that of pseudo first order modified by the fraction of reaction of the intermediate methylcesium that reacts with CHA- $d$ to return to reactant. This back-reaction is represented by the use of $n_{D}$, the mole fraction of deuterium in the solvent CHA, and is modified by $\lambda$, the primary isotope effect, $k_{\mathrm{H}} / k_{\mathrm{D}}$. Eq. 2 was converted into the corresponding finite difference equation, and cells for all components were calculated at each time interval from the preceding time. From eq. 2 the calculation of $\mathrm{D}_{1}$ cells at time $\mathrm{t}+\Delta \mathrm{t}$ from cells at time $\mathrm{t}$ is given as eq. 3, using operation symbols defined in Excel.

$\mathrm{D}_{1}(\mathrm{t}+\Delta \mathrm{t})=\mathrm{D}_{1}(\mathrm{t})+\left(\left(\mathrm{n}_{\mathrm{D}} /\left(\mathrm{n}_{\mathrm{D}}+\lambda^{*} \mathrm{n}_{H}\right)\right)^{\star}\left(4^{\star} \lambda^{\star} \mathrm{D}_{0}(\mathrm{t})-\mathrm{D}_{1}(\mathrm{t})\right)-\mathrm{D}_{1}(\mathrm{t})\right)^{\star} k_{\mathrm{D}}{ }^{*} \Delta \mathrm{t}$

The only parameters are $\lambda$ and $k_{\mathrm{D}}$. The isotope effect $\lambda$ enters in only a small correction term, and these results are not sensitive to the value used, $\lambda=4$ (vide infra). The rate constant $k_{\mathrm{D}}$ was varied to give best agreement with the experimental points. It was found generally that at about $10^{6}$ ss rates tended to slow more than expected from the simulations. We attribute this behavior to some quenching of the base catalyst at such long times. Figure 2 shows the agreement obtained for the best value $k_{\mathrm{D}}=5.6 \mathrm{E}-7 \mathrm{~s}^{-1}$, together with results for $k_{\mathrm{D}}=5 \mathrm{E}-7$ and $6 \mathrm{E}-7 \mathrm{~s}^{-1}$, indicating that the result is reliable to about $\pm 10 \%$. A further correction is necessary because only part of the methane is in solution. From the known Henry's Law constant for methane in $\mathrm{CHA},{ }^{10} 0.349$ is in solution giving a corrected $k_{\mathrm{D}}=1.60 \mathrm{E}-6 \mathrm{~s}^{-1}$. The concentration of CsCHA was $0.030 \mathrm{M}$ giving $k_{2}(\mathrm{D})=5.3 \mathrm{E}-5 \mathrm{M}^{-1} \mathrm{~s}^{-1}$ (Table 1 ).

Table 1. Summary of kinetic runs with $\mathrm{CH}_{3} \mathrm{D}$ in $\mathrm{CHA}$ or $\mathrm{CH}_{4}$ in $\mathrm{CHA}-d_{2}$ catalyzed by $\mathrm{CsCHA}$ at $50{ }^{\circ} \mathrm{C}$

\begin{tabular}{|c|c|c|c|c|c|c|c|}
\hline Run & Process & $\begin{array}{c}\text { [CsCHA] } \\
{[\mathrm{M}]}\end{array}$ & $\begin{array}{c}\text { Amount } \mathrm{CH}_{4} \\
{[\mathrm{mmol}]} \\
\end{array}$ & $\begin{array}{c}\text { Amount CHA } \\
{[\mathrm{mmol}]}\end{array}$ & $\mathrm{f}\left(\mathrm{CH}_{4}\right)^{\mathrm{a}}$ & $\begin{array}{c}k_{\mathrm{obs}} \\
{\left[\mathrm{s}^{-1}\right]}\end{array}$ & $\begin{array}{c}k_{2} \\
{\left[\mathrm{M}^{-1} \mathrm{~s}^{-1}\right]}\end{array}$ \\
\hline DRT11 & $k(\mathrm{D})$ & 0.030 & 8.3 & 715 & 0.349 & $5.6 \mathrm{E}-7$ & $5.3 \mathrm{E}-5$ \\
\hline $\mathrm{DRT7}^{\mathrm{b}}$ & $k(\mathrm{H})$ & 0.0156 & 9.15 & 663 & 0.308 & $1.1 \mathrm{E}-6$ & $2.3 \mathrm{E}-4$ \\
\hline DRT8 $^{\mathrm{C}}$ & $k(\mathrm{H})$ & 0.029 & 10.1 & 663 & 0.332 & $1.8 \mathrm{E}--6$ & $1.9 \mathrm{E}-4$ \\
\hline DRT12 & $k(\mathrm{H})$ & 0.041 & 9.9 & 741 & 0.389 & 2.4E-6 & $1.5 \mathrm{E}-4$ \\
\hline
\end{tabular}

${ }^{a}$ Fraction of methane in solution calculated from the volumes of vessel and CHA and the Henry's Law constant for methane. ${ }^{\mathrm{b}}$ Run included ethane $(16.3 \mathrm{mmol})$ and neopentane (46.7 mmol). ${ }^{\text {C }}$ Run included cyclopropane (55.0 mmol). 


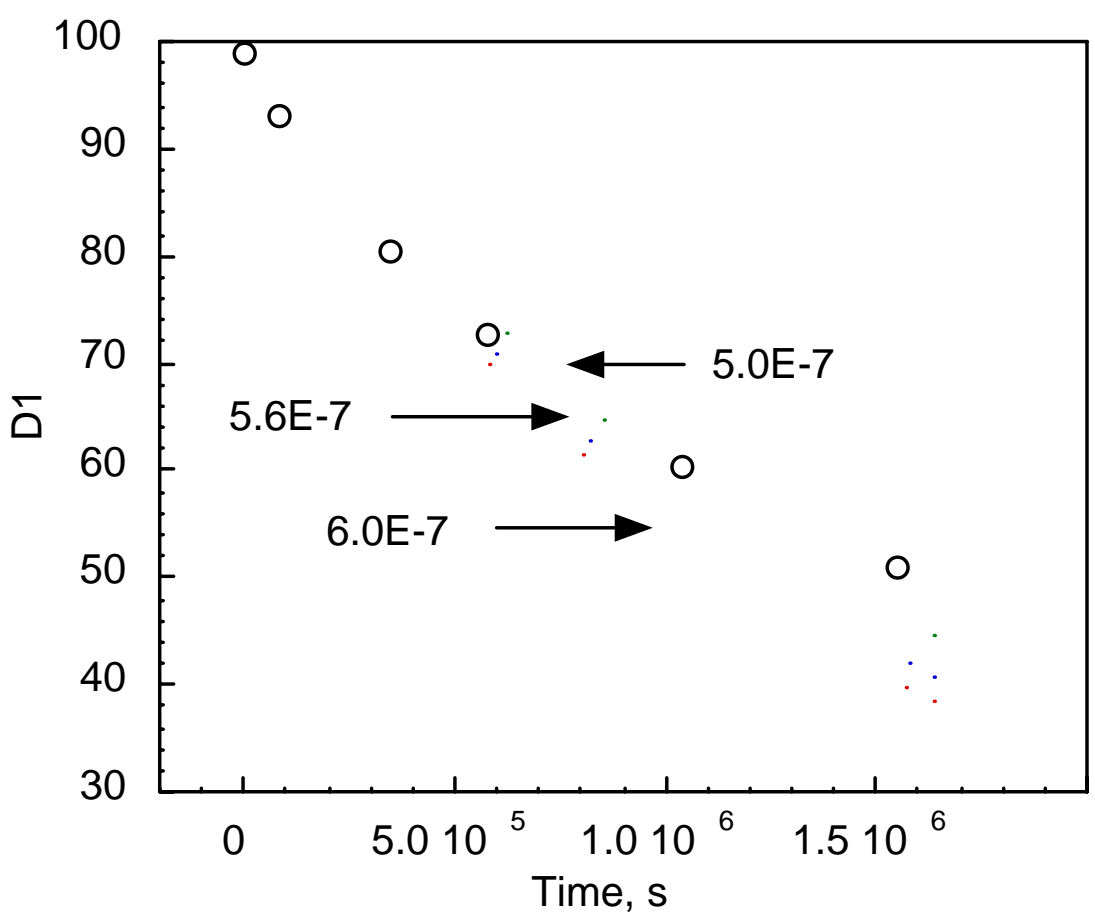

Figure 2. Experimental points (circles) for protodedeuteration run DRT11 with simulations for three different rate constants rate constants given as $\mathrm{s}^{-1}$. Best overall agreement is with the middle curve, $k_{\mathrm{D}}=5.6 \mathrm{E}-7 \mathrm{~s}^{-1}$ but after $10^{6} \mathrm{~s}$ the rates fall off, an effect attributed to slight quenching of the base catalyst at long reactiuon rates.

Deuterodeprotonation. The remaining runs used methane and cyclohexylamine- $\mathrm{N}, \mathrm{N}-\mathrm{d}_{2}(\mathrm{CHA}-$ $d_{2}$ ). The kinetic equations are now more complex because we now must consider multiple deuteration of methane. In run DRT11 the formation of $\mathrm{CH}_{2} \mathrm{D}_{2}$ was negligible and was neglected. In the deuteration runs, however, multiple deuteration must be considered explicitly. For example, $\mathrm{CH}_{3} \mathrm{D}$ is produced not only from the abstraction of deuterium from $\mathrm{CHA}-d$ by $\mathrm{CH}_{3} \mathrm{Cs}$ but also from the reaction of $\mathrm{CH}_{2} \mathrm{DCs}$ with a solvent proton. Scheme 2 shows the formation of $\mathrm{CH}_{3} \mathrm{D}$ and $\mathrm{CH}_{2} \mathrm{D}_{2}$; similar equations are used for the formation of $\mathrm{CHD}_{3}$ and $\mathrm{CD}_{4}$. The steady state approximation was applied to all MeCs intermediates.

The Excel equation for $\mathrm{D}_{1}$, eq. 4, shows the additional complexity required by incorporating the reactions of $\mathrm{CH}_{3} \mathrm{Cs}$ and $\mathrm{CH}_{2}$ DCs. In eq. 4, all of the quantities to the right of the equal sign apply to time $t$ and $\mu=\left(\lambda n_{H} / n_{D}\right) /\left(\lambda n_{H} / n_{D}\right)+1$.

$$
D_{1}(t+\Delta t)=D_{1}(t)+\left(\left(-\left(3^{\star} D_{1} / \delta\right)-\left(D_{1} / \lambda\right)+(1-\mu)^{\star}\left(4^{*} D_{0}+\left(D_{1} / \lambda\right)\right)+\mu^{\star}\left((3 / \delta)^{*} D_{1}+(2 / \lambda)^{\star}\left(D_{2} / \delta\right)\right)\right)^{\star} k_{H}^{*} \Delta t\right.
$$


Similar equations can be derived for the deuterated methanes, $\mathrm{D}_{1}\left(\mathrm{CH}_{3} \mathrm{D}\right), \mathrm{D}_{2}\left(\mathrm{CH}_{2} \mathrm{D}_{2}\right), \mathrm{D}_{3}$ $\left(\mathrm{CHD}_{3}\right)$ and $\mathrm{D}_{4}\left(\mathrm{CD}_{4}\right)$. In the reactions of these species the $\alpha$-secondary isotope effect needs to be considered; that is, removal of a proton from $\mathrm{CH}_{3} \mathrm{D}$ is slower than from $\mathrm{CH}_{4}$. The magnitude of this effect was shown to be $\delta=k(\mathrm{H}) / k(\mathrm{D})=1.2$ in the protodedeuteration reactions of $\mathrm{Ph}_{3} \mathrm{CCH}_{2} \mathrm{D}$ and $\mathrm{Ph}_{3} \mathrm{CCD}_{3}$ with CsCHA. ${ }^{11}$

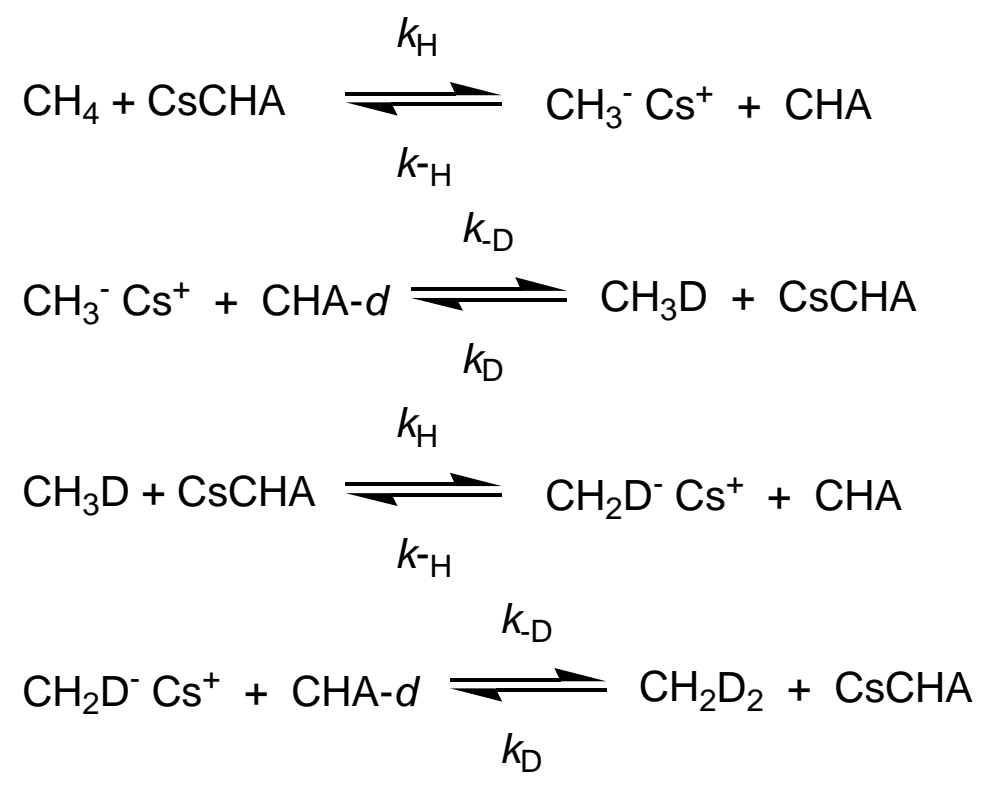

\section{Scheme 2}

Run DRT7 included ethane and neopentane whose relative rates will be discussed in a subsequent paper. The results of this run are summarized in Table 1 and compared to the best simulations in Figure 3. Note that the $k_{\mathrm{H}}$ are given as rates per hydrogen. Again, only data up to about $10^{6} \mathrm{~s}$ were used in the simulations.Run DRT8 included cyclopropane, which is more reactive than methane, and was run over a shorter period. The conversion to polydeuterated methanes, while still substantial, was less than in run DRT7. The methane results are also summarized in Table 1 and Figure 4. Run DRT12 was a run with methane alone and its results are summarized in Table 1 and Figure 5.

All of the runs involving multideuteration show good agreement with the simulations, particularly considering that only one rate constant is required as an adjustable parameter. The two primary and secondary isotope effects also required are taken from other data and could be varied, in any event, only within rather narrow limits. Both have much smaller effects on the simulations than do the rate constants.

The pseudo-first order rate constants were converted into second order rate constants by dividing by [CsCHA]. The $k_{2}$ values for the deuterodeprotonation runs show some scatter indicative of the combined experimental errors in these kinetics, particularly in measuring [CsCHA]. The average value, $k_{2}=1.9 \pm 0.3 \mathrm{M}^{-1} \mathrm{~s}^{-1}$ combined with the protodedeuteration result 
from DRT11 gives $k_{\mathrm{H}} / k_{\mathrm{D}}=3.6 \pm 0.6$, in good agreement with that derived for $\mathrm{CPh}_{3} \mathrm{CH}_{3}$, 3.84.0. ${ }^{11}$ The latter result comes from $k_{\mathrm{D}} / k_{\mathrm{T}}$ in CHA solution. The present result involves a $k_{\mathrm{D}}$ in CHA and $k_{\mathrm{H}}$ in CHA- $d_{2}$ and could contain a solvent isotope effect. LiCHA in CHA- $d_{2}$ is known to be more reactive than in $\mathrm{CHA}^{7}$ but the lithium amide is aggregated and only the small amount of monomer present is the active catalyst. The solvent isotope effect in that case is probably an effect on the aggregation equilibrium. CsCHA is known to be monomeric and its solvent isotope effect is likely to be small. Any substantial isotope effect would be in the direction to reduce $k_{\mathrm{H}} / k_{\mathrm{D}}$ and this value is already at the low end. The corresponding isotope effect for cyclohexane is 4.6. ${ }^{11}$ The rounded value of 4 was assumed for the present kinetic simulations.

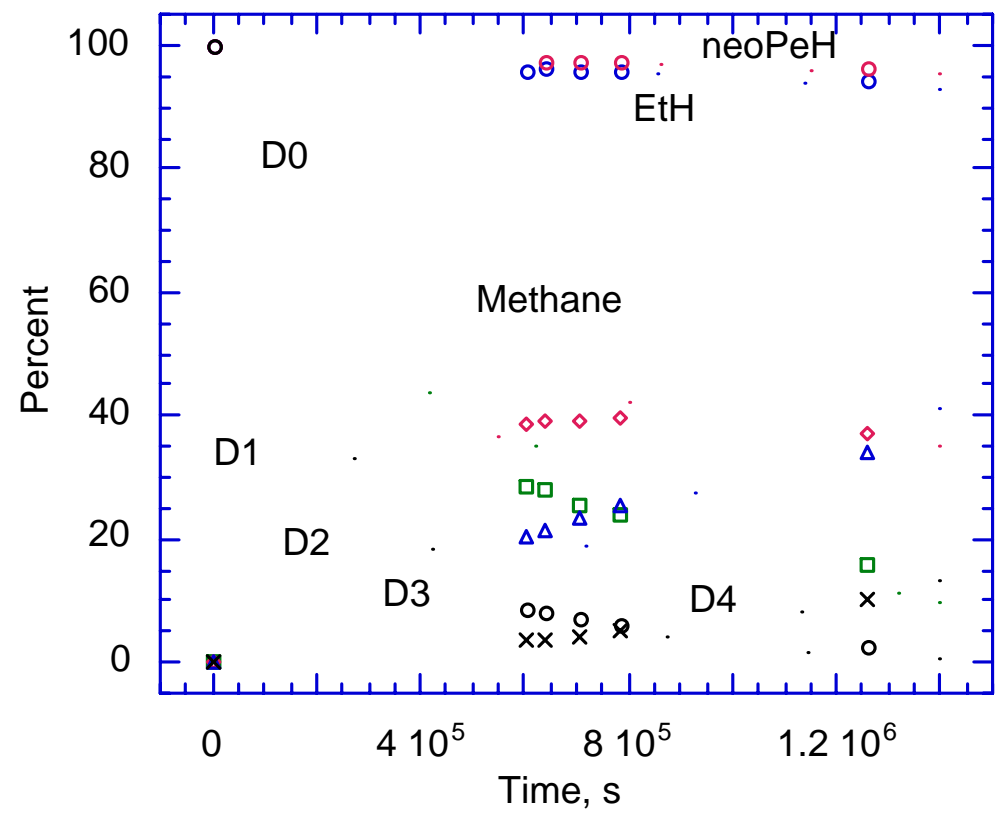

Figure 3. Run DRT7 compared to simulations using $k_{\mathrm{H}}(\mathrm{EtH})=1.05 \mathrm{E}-8, k_{\mathrm{H}}($ neoPeH $)=3.3 \mathrm{E}-9$ and $k_{\mathrm{H}}\left(\mathrm{CH}_{4}\right)=1.1 \mathrm{E}-6 \mathrm{~s}^{-1} ; \lambda=4$. Symbols for methane: circles, $\mathrm{D}_{0}$; squares, $\mathrm{D}_{1}$; diamonds, $\mathrm{D}_{2}$; triangles, $\mathrm{D}_{3} ; \mathrm{x}$ 's, $\mathrm{D}_{4}$.

The second order $k_{\mathrm{D}}$ value for DRT11 can be compared to that derived for cyclohexane, $k_{2}(\mathrm{D})=7.6 \mathrm{E}-9 \mathrm{M}^{-1} \mathrm{~s}^{-1}$, ${ }^{11}$ giving a relative reactivity of $7.0 \mathrm{E}+3$. This reactivity is substantially larger than the preliminary figure published years ago. ${ }^{2}$ Methane is of comparable reactivity to 1,1,1-triphenylethane, (rel rate $k_{\mathrm{D}}\left(\mathrm{CH}_{3} \mathrm{D}\right) / k_{\mathrm{D}}\left(\mathrm{Ph}_{3} \mathrm{CCH}_{2} \mathrm{D}\right)=0.82$ ), an important bridge compound whose study also provided isotope effects discussed above. ${ }^{11}$ The comparable magnitude of the primary isotope effects over this broad range of reactivity suggests that the mechanism for proton exchange is essentially the same for all of these hydrocarbons. Further comparisons of relative kinetic acidities will be deferred to the next paper but a comparison with benzene would be appropriate at this time. Benzene- $d$ with $\mathrm{CsCHA}^{4}$ has $k_{\mathrm{D}}=0.135 \mathrm{M}^{-1} \mathrm{~s}^{-1}$ and is therefore $2.5 \mathrm{E}+3$ more reactive than methane- $d$. 


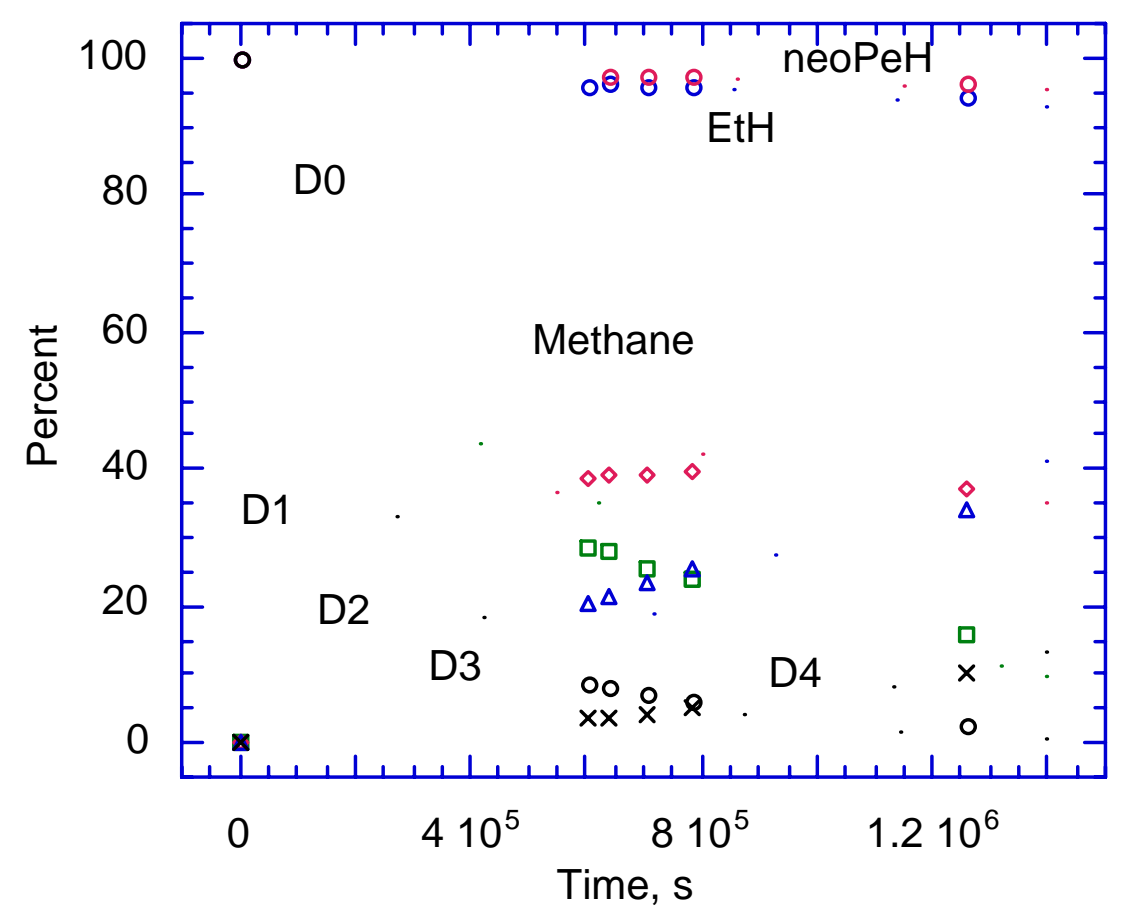

Figure 4. Experimental points and kinetic simulation for run DRT8; $k_{\mathrm{H}}=1.8 \mathrm{E}-6, \lambda=4, \delta=1.2$. Symbols as in Fig. 3.

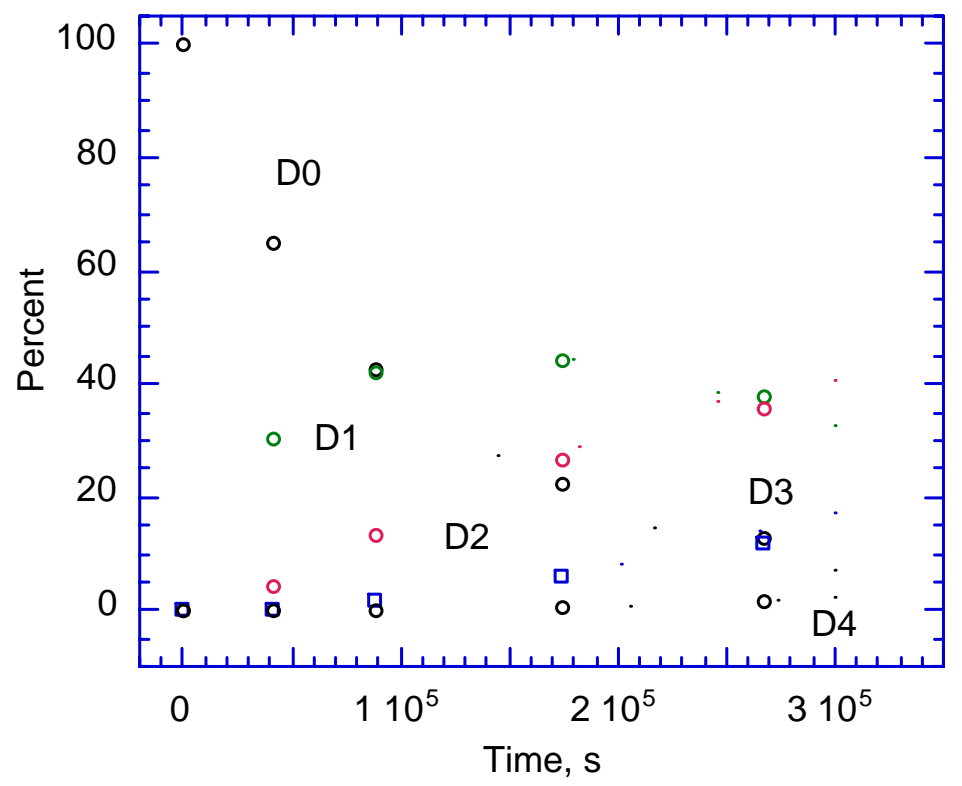

Figure 5. Experimental points and simulated kinetics for run DRT12. Black circles, $\mathrm{D}_{0}$; green circles, $\mathrm{D}_{1}$; red circles, $\mathrm{D}_{2}$; blue circles, $\mathrm{D}_{3}$; green at bottom, $\mathrm{D}_{4}$. 


\section{Experimental Section}

Methane- $\boldsymbol{d}$ and methane- $\boldsymbol{d}_{3}$. Methyl bromide and magnesium turnings were allowed to react in degassed diethyl ether, cooled in a dry ice-isopropanol mixture, and $\mathrm{D}_{2} \mathrm{O}$ was added. Methane- $d$ was collected in a storage bulb and dried over $\mathrm{P}_{2} \mathrm{O}_{5}$. Methane- $d_{3}$ was made in the same way from $\mathrm{CD}_{3} \mathrm{Br}$. These compounds were analyzed by low voltage mass spectroscopy and used to calibrate the high voltage, high resolution, mass spectrometer used for many of the runs with mixed alkanes.

Kinetics. The kinetic runs made use of the stainless steel bomb-type reactor pictured in Figure 1. Greaseless bellows valves (Nupro H series) A and C were welded to a bomb of about $120 \mathrm{~mL}$ capacity. The glass ball joint B for attachment to a vacuum system was connected via a glass-tometal seal. The metal thread was wrapped with Teflon tape. The base solution in cyclohexylamine was sealed in a glass vial and placed in the bomb together with a steel ball. After evacuating and weighing the bomb and contents, cyclohexylamine and volatile hydrocarbons were transferred on the vacuum line and the bomb was finally pressured with argon at $-80{ }^{\circ} \mathrm{C}$. After equilibrating in a $50{ }^{\circ} \mathrm{C}$ bath the bomb was vigorously shaken to break the glass tube and start the run. A small amount was ejected through stain steel tube $\mathrm{D}$ and valve $\mathrm{C}$ into a tube containing a small amount of an indicator hydrocarbon, such as 4,5-methylenephenanthrene, whose anion is highly colored. The production of color indicated that the glass tube had broken and reaction had started. The first point was taken by removing a small amount of gas through A and B for mass spectral analysis. At intervals additional gas samples were taken and analyzed.

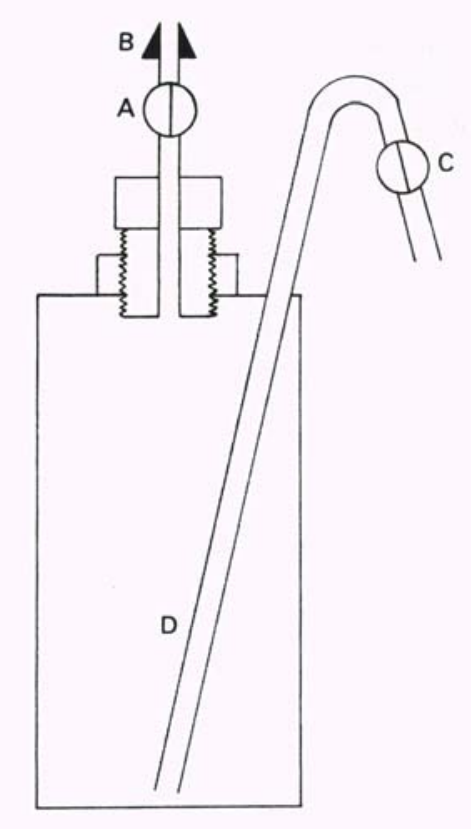

Figure 1. Stainless steel bomb used for the kinetic runs. 
Cyclohexylamine-N,N-d $\boldsymbol{d}_{2}$. The preparation has been described previously. ${ }^{7}$ Cesium cyclohexylamide-N- $d$ was prepared by reaction with cesium metal. Note, however, that this reaction is much slower than the reaction of cesium metal with undeuteriated cyclohexylamine.

\section{Conclusions}

Using a small stainless steel bomb and analysis of results using Excel spreadsheets, the exchange kinetics were studied of methane in cyclohexylamine catalyzed by cesium cyclohexylamide. The primary isotope effect is normal and the kinetic acidity of methane is about midway between that of cyclohexane and benzene.

\section{Acknowledgments}

The present work was supported by grants from the National Science Foundation.

\section{References}

1. Carbon Acidity. 118.

2. Streitwieser, A. Jr.; Taylor, D. R. Chem. Commun. 1970, 1248.

3. Streitwieser, A. Jr.; Young, W. R. J. Am. Chem. Soc 1969, 91, 529.

4. Streitwieser, A. Jr.; Young, W. R.; Caldwell, R. A. J. Am. Chem. Soc. 1969, 91, 527.

5. Streitwieser, A. Jr.; Caldwell, R. A.; Young, W. R. J. Am. Chem. Soc. 1969, 91, 529.

6. Dixon, R. E.; Streitwieser, A.; Laidig, K. E.; Bader, R. F. W.; Harder, S. J. Phys. Chem 1993, 97, 3728.

7. Streitwieser, A. Jr.; Owens, P. H.; Sonnichsen, G.; Smith, W. K.; Ziegler, G. R.; Niemeyer, H. M.; Kruger, T. L. J. Am.Chem. Soc. 1973, 95, 4254.

8. Streitwieser, A. Jr.; Van Sickle, D. E.; Langworthy, W. C. J. Am.Chem. Soc. 1962, 84, 244.

9. Billo, E. J. Excel for Chemists; $2^{\text {nd }}$ Edn; ed.; J. Wiley \& Sons, Inc.: New York, N.Y., 2001.

10. Keevil, T. A.; Taylor, D. R.; Streitwieser, A. Jr. J. Chem. Eng. Data 1978, 23, 237.

11. Dixon, R. E.; Streitwieser, A. J. Org. Chem. 1992, 57, 6125. 